\title{
Estruturação de ambientes virtuais de aprendizagem para suporte na aplicação virtual da metodologia PBL
}

\author{
Rebeca dos Santos \\ Instituto Federal da Bahia \\ Santo Antônio de Jesus, Bahia, Brasil \\ beekahjesus18@gmail.com \\ Igo Amauri Luz \\ Instituto Federal da Bahia \\ Santo Antônio de Jesus, Bahia, Brasil \\ igo.luz@ifba.edu.br
}

\author{
Fernanda Silveira \\ Instituto Federal da Bahia \\ Santo Antônio de Jesus, Bahia, Brasil \\ nandasilva36m@gmail.com \\ Fernanda Santana \\ Instituto Federal da Bahia \\ Feira de Santana, Bahia, Brasil \\ fernandacastelo@ifba.edu.br
}

Em decorrência da pandemia da COVID-19, declarada pela Organização Mundial de Saúde (OMS) [8], o Instituto Federal da Bahia (IFBA) suspendeu as atividades presenciais por tempo indeterminado. De forma a miniminizar os impactos, o IFBA regulamentou a implementação de Atividades de Ensino Não Presenciais Emergenciais (AENPE) durante a pandemia. Neste cenário pandêmico, dentre os desafios enfrentados na aplicação do ensino remoto, destaca-se: a adaptação da metodologia de ensino presencial ao contexto não presencial; a utilização de ferramentas tecnológicas; os impactos de cunho pessoal, financeiro e psicológico; os elevados índices de evasão [1]; entre outros.

No contexto das atividades de ensino não presenciais do IFBA, os autores deste resumo tiveram a ideia de analisar diferentes Ambientes Virtuais de Aprendizagem (AVA) [9] e propor, dentro destes, um modelo de espaço virtual de trabalho para executar a metodologia PBL (Aprendizagem Baseada em Problemas e Projetos, do inglês Problem-Based Learning). Devido a disponibilidade de forma institucional, os AVA objeto de estudo deste trabalho são: Microsoft Teams, Google Classroom (GSuite) e Moodle.

A motivação em propor esse projeto surgiu na relação entre Ambientes Virtuais de Aprendizagem e Metodologias Ativas, mais especificamente o $\mathrm{PBL}$, e no fato de que os AVA disponíveis no IFBA não foram desenvolvidos com foco em serem utilizados com metodologias ativas de ensino. Dessa forma, surgiram questionamentos, como: Existe alguma ferramenta tecnológica voltada para a execução do PBL de forma remota? Alguma das ferramentas disponíveis hoje no mercado possibilitam a execução do PBL de forma satisfatória? Quais seriam os desafios tecnológicos envolvidos na aplicação do PBL de forma remota?

O PBL propõe que, a partir de situações problemas do mundo real, os discentes produzam seus próprios planos para encontrar uma solução [3, 4] e, assim, adquiram conhecimentos e desenvolvam diferentes habilidades $[2,5,6]$. A execução do PBL de forma remota [7] exige que o AVA disponha de recursos que garantam

Fica permitido ao(s) autor(es) ou a terceiros a reprodução ou distribuição, em parte ou no todo, do material extraído dessa obra, de forma verbatim, adaptada ou remixada, bem como a criação ou produção a partir do conteúdo dessa obra, para fins não comerciais, desde que sejam atribuídos os devidos créditos à criação original, sob os termos da licença CC BY-NC 4.0.

EduComp'21, Abril 26-30, 2021, Jataí, Goiás, Brasil (On-line)

(c) 2021 Copyright mantido pelo(s) autor(es). Direitos de publicação licenciados à Sociedade Brasileira de Computação (SBC). a implementação das características da metodologia, como: a formação dos grupos tutoriais, a execução das sessões tutoriais e que os atores possam desempenhar seus papeis de forma satisfatória. Dentre os recursos tecnológicos essenciais, temos: ferramenta que possibilite momentos síncronos de discussão; Compartilhamento de conteúdo em formato digital; ferramenta para edição de texto de forma online; quadro digital colaborativo; mecanismos para uma comunicação dinâmica entre os membros atores, inclusive durante a realização online da sessão tutorial; entre outros.

A ideia de que trata este resumo começou a ser aplicada em 2020, quando o IFBA iniciou as ofertas de AENPE. Em um primeiro momento, os docentes decidiram aplicar o PBL de forma remota em duas diferentes turmas do IFBA, são elas: no componente curricular "Arquitetura de Computadores e Software Básico" dos cursos de Redes de Computadores e Análise e Desenvolvimento de Sistemas do Campus Santo Antônio de Jesus e na atividade extracurricular "Desenvolvendo Games com Godot Engine" ofertada para os alunos do curso de Sistemas de Informação do Campus Feira de Santana. A situação problema proposta aos discentes matriculados estava relacionada ao contexto da pandemia da COVID-19 e o AVA utilizado em ambas as turmas foi o Microsoft Teams.

Antes de iniciar as sessões tutorias, foram levantados os recursos tecnológicos disponíveis no Teams. A partir de então, a equipe do projeto estruturou o espaço virtual da sala de aula, iniciou a aplicação do PBL e ficou a disposição para auxiliar os discentes com a utilização das ferramentas. Como continuidade ao projeto, pretende-se, ainda, investigar os recursos disponíveis no Google Classroom e no Moodle e propor a estrutura para a execução do PBL em ambos os AVA. Como produto do projeto, serão desenvolvidos manuais de usuário para guiar outros educadores a utilizarem os AVA para dar suporte ao PBL.

\section{AGRADECIMENTOS}

Os autores agradecem ao Instituto Federal da Bahia (IFBA) pelo apoio financeiro.

\section{REFERENNCIAS}

[1] ABED. 2021. Censo ead.br: relatório analítico da aprendizagem a distância no Brasil. http://abed.org.br/arquivos/CENSO_EAD_2019_PORTUGUES.pdf. (Accessed on 04/13/2021).

[2] Michele Angelo, E Fabiana, and Cristina Bertoni. 2011. Análise da Aplicação do Método PBL no Processo de Ensino e Aprendizagem em Um Curso de Engenharia 
de Computação. Revista de Ensino de Engenharia 30 (12 2011). https://doi.org/10. 15552/2236-0158/abenge.v30n2p35-42

[3] R. Delisle, Association for Supervision, and Curriculum Development. 1997. How to Use Problem-based Learning in the Classroom. ASCD. https://books.google.com. br/books?id=9nZPZ6N27EEC

[4] David Moises Barreto dos Santos, GRPR Pinto, Claudia Pinto Pereira Sena, Fabi ana Cristina Bertoni, and Roberto Almeida Bittencourt. 2007. Aplicação do método de aprendizagem baseada em problemas no curso de engenharia da computação da universidade estadual de feira de santana. In Congresso Brasileiro de Educação em Engenharia-COBENGE.

[5] L. C. B. C. Ferreira, O. C. Branquinho, P. R. Chaves, P. Cardieri, F. Fruett, and M. D. Yacoub. 2019. A PBL-Based Methodology for IoT Teaching. IEEE Communications Magazine 57, 11 (2019), 20-26. https://doi.org/10.1109/MCOM.001.1900242
[6] Lucia Giraffa and Luana Müller. 2017. Metodologia baseada em sala de Aula invertida e Resolução de Problemas relacionado ao cotidiano dos estudantes: uma proposta para ensinar programação para iniciantes. International fournal on Computational Thinking (IFCThink) 1 (10 2017), 52. https://doi.org/10.14210/ ijcthink.v1.n1.p52

[7] Keunsoo Lee. 2018. A Study on the Application of Google Classroom for ProblemBased Learning. Journal of the Korea Academia-Industrial cooperation Society 19 (01 2018), 81-87. https://doi.org/10.5762/KAIS.2018.19.7.81

[8] World Health Organization. 2021. WHO | World Health Organization. https: //www.who.int/. (Accessed on 03/28/2021).

[9] A.T.C. Pereira. 2007. Ambientes virtuais de aprendizagem em diferentes contextos. Ciência Moderna. https://books.google.com.br/books?id=CrWTZwEACAAJ 